\title{
PENERAPAN PENDEKATAN MONTESSORI UNTUK MENANAMKAN PEMAHAMAN KONSEP BILANGAN CACAHPADA SISWA TK PUTERA ZAMAN MALANG
}

\author{
Dyah Ayu Sulistyaning Cipta \\ IKIP Budi Utomo Malang \\ dyahayu.esce@gmail.com
}

\begin{abstract}
Abstrak
Mengajarkan pelajaran berhitung kepada siswa TK seringkali dianggap tabu. Sebagian orang beranggapan bahwa tidak boleh mengajarkan pelajaran berhitung kepada anak yang belum genap usia tujuah tahun. Perdebatan yang panjang muncul akhibat adanya tes masuk SD yang berisikan soal-soal berhitung. Benarkah siswa TK sama sekali tidak diperkenankan mengenal pelajaran berhitung? Tujuan dari penelitian ini adalah untuk mengenalkan pendekatan montessori, sebuah pendekatan yang layak digunakan untuk mengajarkan konsep berhitung pada siswa TK.

Penelitian ini merupakan penelitian deskriptif kualitatif yang dilakukan pada siswa TK A Putera Zaman. Penelitian diawali dengan melakukan observasi dan wawancara, kemudian dilanjutkan dengan penerapan pendekatan montessori dalam pembelajaran yang dilakukan bersama guru di kelas.

Hasil penelitian dengan berpijak pada pendapat Maria Montessori bahwa usia dini hingga usia enam tahun merupakan fase Absorbent Minds, otak anak akan terus berubah, berkembang pesat, dan terbuka terhadap stimulasi-stimulasi baru, maka baiknya siswa TK A pun telah belajar berhitung. Beberapa tahapan untuk menanamkan konsep bilangan cacah kepada siswa TK A Putera Zaman dapat dilakukan dengan langkah-langkah penyampaian materi berikut: (1) Pengenalan terhadap kuantitas $1-10$, (2) Mengenal nol, (3) Mencocokkan angka dengan kuantitas $0-10$, (4) Relasi diantara bilangan $1-10$, (5) Operasi penjumlahan dasar, dan (6) Operasi pengurangan dasar. Hasil dari penanaman konsep bilangan cacah dengan menggunakan pendekatan montessori adalah siswa dapat menggunakan matematika berdasarkan penalaran, bukan sekedar berhitung tanpa logika.
\end{abstract}

Kata kunci: montessori, penanaman konsep, bilangan cacah, berhitung pada usia TK

\begin{abstract}
Teaching counting lessons to kindergarten students is often considered taboo. Some people assume that should not teach counting lessons to children who have not even reached the age of seven years. A long debate arose due to an elementary school admission test that contained numerical questions. Is it true that kindergarten students are not allowed to learn numeracy lesson? The purpose of this study is to introduce a montessori approach, a feasible approach used to teach the concept of counting in kindergarten students.

This research is a qualitative descriptive research conducted on TK A Putera Zaman students. The research begins with the conduct of obeservasi
\end{abstract}


and interview, then proceed with applying montessori approach in learning done with teacher in class.

The results of the research with the stand on the opinion of Maria Montessori that the early age to the age of six years is the phase Absorbent Minds, the child's brain will continue to change, grow rapidly, and open to new stimuli, so kindergarten A students have learned to count. Some steps to embed the concept of counting to the students of Kindergarten A Putera Zaman can be done with the following delivery steps: (1) Introduction to quantity $1-10$, (2) What is zero, (3) Matching numbers with quantity $0-10$, (4) Relation of $1-10$, (5) Basic sum operation, and (8) Basic reduction operation. The result of cultivating the concept of chopping with montessori approach is that students can use mathematics based on reasoning, not just counting without logic.

Keywords: montessori, concept, whole number, counting atkindergarten

Sitasi: Cipta, D. A. S. 2018. Penerapan Pendekatan Montessori untuk Menanamkan Pemahaman Konsep Bilangan Cacah pada Siswa TK Putera Zaman Malang. Matematika dan Pembelajaran, 6(1), 29-34.

\section{PENDAHULUAN}

Berbicara tentang pelajaran berhitung untuk siswaTaman Kanak-kanak (TK) memang merupakan hal yang sangat sensitif. Di satu sisi, kita akan dihadapkan pada sebuah idealisme bahwa anak akan siap menerima pelajaran membaca, menulis, dan berhitung (calistung) saat ia telah duduk di bangku Sekolah Dasar (SD). Tapi di sisi lain, seringkali kita temui bahwa SD swasta ternama selalu mengadakan tes calistung dalam seleksi penerimaan siswa barunya. Dalam hal ini, tentu saja akan ada calon siswa yang diterima dan ditolak berdasarkan hasil tes calistung tersebut.

Perdebatan panjang yang tak pernah usai selalu terjadi ketika siswa TK telah mendapatkan pelajaran calistung. Di satu sisi, banyak orang menganggap hal itu salah sehingga para orang tua mulai berburu sekolah TK yang tidak mengajarkan calistung sama sekali. Namun di sisi lain, orang tua pasrah menerima keadaan, saat anak belajar calistung di TK demi dapat bersekolah di SD favorit. Tapi benarkah calistung memang tidak diperkenankan untuk dipelajari oleh siswa TK?

Kusumo (2017: 10) menyebutkan bahwa matematika bisa dikenalkan kepada anak mulai sejak usia tiga tahun. Lebih lanjut lagi, ia menyatakan bahwa periode sensitif anak terhadap angka dimulai dari usia tiga tahun. Hal tersebut sejalan dengan pernyataan Montessori (2015: 79) bahwa usia dini hingga usia enam tahun merupakan fase Absorbent Minds, otak anak akan terus berubah, berkembang pesat, dan terbuka terhadap stimulasistimulasi baru. Dengan berpijak pada kedua pendapat tersebut, bukankah seharusnya sahsah saja jika pelajaran berhitung diberikan pada usia TK?

TK Putera Zaman merupakan TK yang memasukkan pembelajaran calistung ke dalam kurikulum pembelajarannya, terbukti siswa lulusan TK Putera Zaman telah mampu membaca, menulis, dan berhitung, serta mampu lulus dalam mengikuti tes masuk SD dengan materi calistung. Namun demikian, melalui observai yang dilakukan peneliti sebelum melakukan penelitian, ia mendapati siswa yang membilang $1-20$ secara berurutan 
sembari memasuki kelas, padahal ketika itu konsep pengenalan terhadap kuantitas $1-20$ belum dikenalkan kepada siswa.

Berdasar pada observasi sederhana tersebut, untuk menghindari kesalahan konsep pada siswa dalam mempelajari bilangan, peneliti tertarik untuk menggunakan pendekatan montessori. Diharapkan dengan pendekatan motessori ini siswa dapat mengenal bilangan dan operasinya secara mengalir dan natural saja seperti kehidupan sehari-hari.

Penelitian ini membahas bagaimana agar berhitung menjadi layak untuk diajarkan pada siswa TK. Menekankan tentang matematika yang seperti apa yang tepat diajarkan pada siswa TK. Pelajaran membaca dan menulis yang diberikan kepada siswa TK tidak dibahas di sini.

\section{METODE}

Penelitian ini merupakan penelitian deskriptif kualitatif. Sugiyono (2016: 15) menyebutkan penelitian kualitatif merupakan metode penelitian yang berlandaskan pada filsafat postpositivme yang digunakan untuk meneliti kondisi obyek alamiah, dimana peneliti sebagai instrument kunci, pengambilan sampel sumber data dilakukan secara purposive dan snowball, teknik pengumpulan dengan triangulasi (gabungan), analisis data bersifat induktif/kualitatif, dan hasil penelitian lebih menekankan makna dari pada generalisasi. Penelitian deskriptif kualitatif yang digunakan pada penelitian ini dimaksudkan untuk memperoleh informasi mengenai kemampuan pemahaman konsep bilangan cacah dan operasi hitungnya, yaitu penjumlahan dan pengurangan bilangan cacah dengan pembelajaran menggunakan pendekatan montesssori pada siswa TK Putera Zaman.

Waktu pelaksanaan penelitian ini adalah Januari - Maret 2018. Penelitian dilakukan kepada 20 siswa TK A Putera Zaman. TK Putera Zaman adalah sebuah TK yang terletak di Kecamatan Lowokwaru Kota Malang.

Penelitian diawali dengan melakukan obeservasi dan wawancara kepada guru TK Putera Zaman, kemudian dilanjutkan dengan penerapan pendekatan montessori dalam pembelajaran yang dilakukan bersama guru di kelas. Selanjutnyaanalisa data dalam penelitian ini dilakukan melalui tiga aktivitas, yaitu data reduction, data display, dan conclusion drawing/verification.

\section{HASIL DAN PEMBAHASAN}

Pendekatan montessori adalah sebuah pendekatan pembelajaran yang dibawa oleh Maria Montessori. Konsep Montessori tentang peran guru berbeda dari konsep yang tradisional. Jika sebelumnya guru menguasai panggung utama kelas sebagai titik fokus perhatian siswa, Montessori mengubah peran tersebut dengan memandu siswa dalam kegiatan belajarnya. Guru harus dapat memandu siswa dalam pengembangan diri, melakukan pengamatan klinis, peka terhadap kesiapan siswa dan tahapan perkembangannya. Guru juga harus menyiapkan lingkungan yang memadai dengan perlengkapan dan bahan yang sesuai, serta mampu bekerja sama dengan siswa dalam pendidikan mandiri mereka. 
Merujuk dari kalimat Montessori yang diambil dari observasi Blaise Pascal, Kusumo (2017: 13) menyebutkan bahwa anak-anak secara natural terlahir dengan mathematical mind. Seiring waktu dan tumbuh kembang mereka, anak-anak mulai peka terhadap jumlah dan mulai ingin berhitung. Pada tahapan ini, anak-anak mulai penasaran pada angka-angka. Terlihat dari bahasa sehari-hari yang digunakan, seperti "Aku bisa naik sepeda roda dua." Nah, mengikuti tahapan perkembangan itulah, maka dalam penelitian ini pengenalan dan pemahaman konsep bilangan cacah akan diberikan secara mengalir, mengikuti pola berpikir siswa TK.

Bahasan materi yang diberikan untuk mengenalkan siswa TK A terhadap konsep bilangan cacah dan operasinya adalah sebagai berikut: (1) Pengenalan terhadap kuantitas 1 - 10, (2) Mengenal nol, (3) Mencocokkan angka dengan kuantitas 0 - 10, (4) Relasi diantara bilangan $1-10$, (5) Operasi penjumlahan dasar, dan (6) Operasi pengurangan dasar.

Pengenalan terhadap kuantitas 1 - 10 dapat dilakukan dengan memanfaatkan benda yang ada di sekeliling. Banyak benda, bahkan mainan yang ada di sekolah, dapat digunakan untuk mengenalkan konsep dasar kuantitas 1 - 10 secara konkret. Jadi, sebelum dikenalkan pada konsep angka, siswa dikenalkan dulu pada konsep kuantitas. Kenalkan siswa dengan satu papan tulis, dua penghapus, tiga ayunan, lima kursi, dan seterusnya.

Selanjutnya, sejalan dengan pernyataan Zaman (2015) bahwa metode yang dirancang harus disesuaikan dengan kebutuhan siswa untuk merekayasa bahan-bahan yang nyata/jelas sebelum mereka sampai pada tahap konsep abstrak yang berkaitan dengan dunia angka, maka dalam penelitian ini peneliti menggunakan tongkat angka. Ada sepuluh tongkat yang tersusun dari bola-bola kecil dengan panjang yang berbeda-beda, seperti pada gambar 1.

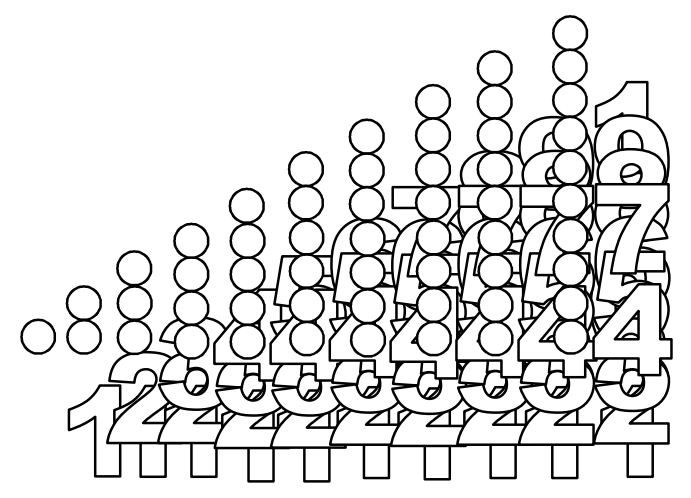

Gambar 1: Tongkat Angka

Sesuai dengan pendekatan montessori, gunakan Three Perion Lesson dalam mengenalkan tongkat angka tersebut. Pertama, katakan "Ini tongkat dua," dengan memberikan penekanan intonasi terhadap pelafalan kata "dua", sambil menunjukkan tongkat yang berisi dua bola. Minta siswa untuk mengulang perkataan "tongkat dua." Lalu hitung secara perlahan, sambil menentuh tongkat, "satu, dua,". Minta siswa untuk mengulangnya. Lakukan pada tongkat angka yang lain, secara berulang hingga siswa mahir. Lanjutkan pada fase berikutnya dengan meminta siswa untuk menunjukkan tongkat 
tiga, lima, dan seterusnya. Jika siswa telah benar-benar mahir makan fase terakhir adalah menanyakan "tongkat berapakah ini?" sambil mngacungkan sebuah tongkat angka.

Dalam kegiatan ini siswa tampak antusias, dia menggunakan panca inderanya, bahkan hingga berteriak, meloncat, mengacungkan tangan. Bebaskan, karena itu adalah fasenya ssuai dengan usianya. Biarkan siswa mengenal matematika dengan cara seru tanpa tuntutan.

Berkenalan dengan nol dapat dilakukan dengan menyiapkan sebuah mangkok beserta bola-bola kecil di dalamnya. Pada tahapan sebelumnya, siswa telah mahir menentukan kuantitas 1 - 10. Maka pada tahapan ini guru dapat mengulanginya lagi dengan menaruh beberapa bola di dalam mangkok, lalu menanyakan ada berapa jumlah bola di dalamnya. Berikutnya, dengan tanpa menaruh bola, tanyakan "Ada berapa bola di dalam mangkok?" Saat siswa menjaab tidak ada, maka katakan bahwa tidak ada itu adalah nol. Minta siswa untuk mengulang kata "nol" dan pastikan ia mengerti bahwa nol adalah tidak ada.

Mencocokkan angka dengan kuantitas 0 - 10 dapat dilakukan dengan menggunakan barang atau mainan yang ada di dalam kelas, misalkan balok-balok kecil, batu-batu kecil, atau apapun. Selanjutnya, urutkan benda tersebut, dan letakkan angka $1-10$ yang mewakili jumlah barang tersebut. Jangan minta siswa mnghafal, namun biarkan ia terbiasa dengan sendirinya. Di luar kegiatan penelitian, guru dapat melanjutkannya dengan menulis angka tersebut dan membuatkan lembar aktivitas (kegiatan ini tidak dibahas dalam penelitian ini).

Tahapan mencocokkan angka dengan kuantitas, membutuhkan waktu yang kebih lama dibandingkan dengan dua tahapan sebelumnya. Hal ini selaras dengan penyataan Kusumo (2017: 57) bahwa tahapan mencocokkan angka dengan kuantitas merupakan kegiatan rutin yang sering dilakukan agar siswa benar-benar memahami konsep kuantitas dan hubungannya dengan konsep angka. Dalam tahapan mencocokkan ini, guru memegang kendali penuh, dan penelitian dilanjutkan saat siswa telah mahir dalam mencocokkan angka dengan kuantitas.

Relasi diantara bilangan $1-10$ merupakan tahapan awal untuk mengenalkan penjumlahan kepada siswa. Pahamkan bahwa suatu bilangan dapat dibentuk dari dua atau lebih bilangan lain yang berbeda. Pada penelitian ini, mainan yang digunakan adalah lego. Tunjukkan bahwa untuk mendapatkan 5 kita dapat menggunakan 2 dan 3 atau 1 dan 4 . Begitu pula dengan bilangan yang lain, tunjukkan dan mainkan seperti pada gambar 2 berikut.
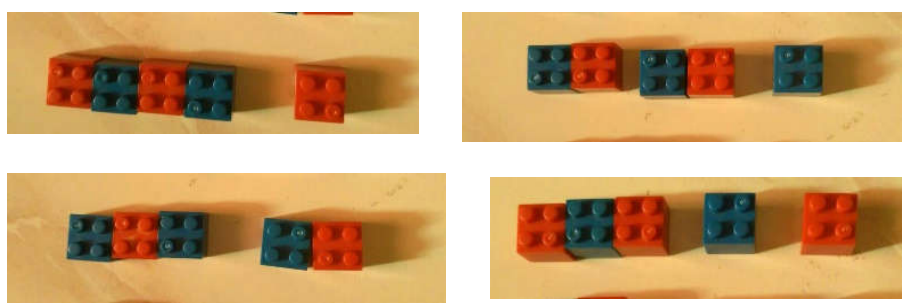

Gambar 2: Cara mendapatkan lima

Tahapan ini mengacu pada hubungan bagian-bagian-keseluruhan yang dikenalkan oleh Van de Well (2008: 131) bahwa untuk mengkonseptualisasikan suatu bilangan seperti 
terdiri dari dua atau lebih bagian adalah hubungan paling penting yang dapat dikembangkan dari bilangan.

Operasi penjumlahan dan pengurangan dasar yang dikenalkan pada siswa TK A Putera Zaman dalam penelitian ini adalah penjumlahan dan pengurangan statis. Penjumlahan berarti menambahkan ke dalam himpunan, misalkan dengan menggunakan mainan yang ada di kelas, bahwa dua balok dan empat balok adalah enam balok. Sedangkan pengurangan adalah mengurangi dari dalam himpunan. Misalkan himpunan yang berisi limabalok dikurangi dikurangi dua balok, maka di dalam himpunan tersisa tiga balok. Dengan diawali menggunakan benda-benda yang konkret, lalu dikenalkan dengan simbol "+" dan "--"dan latihan menggunakan angka hingga siswa mahir mengoperasikan penjumlahan dan pengurangan $1-10$.

Penerapan pendekatan montessori untuk memahamkan konsep bilangan cacah pada siswa TK A Putera Zaman ini adalah siswa dapat menggunakan matematika berdasarkan penalaran, bukan sekedar berhitung tanpa logika. Siswa mengenal bilangan $1-10$ bukan berdasarkan hapalan semata, melainkan telah memahami konsep bilangan secara kuantitas serta mengenal angka sebagai simbolnya.

\section{KESIMPULAN DAN SARAN}

Dengan menggunakan pendekatan montessori, pelajaran berhitung dapat diberikan kepada siswa TK dengan menggunakan langkah-langkah:(1) Pengenalan terhadap kuantitas 1 - 10, (2) Mengenal nol, (3) Mencocokkan angka dengan kuantitas 0 - 10, (4) Relasi diantara bilangan 1 - 10, (5) Operasi penjumlahan dasar, dan (6) Operasi pengurangan dasar. Selanjutnya, dari hasil penelitian disimpulkan bahwa dengan penerapan pendekatan montessori dalam menanamkan pemahaman bilangan cacah, siswa mengenal bilangan $1-10$ bukan berdasarkan hapalan semata, melainkan telah memahami konsep bilangan secara kuantitas serta mengenal angka sebagai simbolnya.

\section{DAFTAR RUJUKAN}

Kusumo, Elviana Lim. (2017). Montessori di Rumah: 55 Kegiatan Matematika. Penerbit Erlangga

Montessori, Maria. (2015). Metode Montessori: Panduan Wajib untuk Guru dan Orangtua

Didik PAUD. (Lazuardi.Terj.). Yogyakarta: Pustaka Pelajar.

Sugiyono. (2016). Metode Penelitian Pendidikan: Pendekatan Kuantitatif, Kualitatif, dan $R \& D$. Bandung: Penerbit Alfabeta.

Van de Walle, John A. (2008). Matematika Sekolah Dasar dan Menengah Jilid 1. Edisi Keenam. (Suyono.Terj.). Jakarta: Erlangga.

Zaman, Badru. (2015). "Pendidikan Ala Montessori", (online), (http://file.upi.edu/Direktori/FIP/JUR._PGTK/197408062001121-

BADRU ZAMAN/Bahan Perkuliahan Pendekatan Montessori.pdf, diakses tanggal 15 Januari 2018) 